daily smoking prevalence data to obtain estimates of future incident case numbers. By applying the calculated PIFs to the projected cancer cases for each policy intervention, we estimated the number of future cancer cases that would be expected under the corresponding scenario.

Results Our preliminary results suggest that over a 30-year period, an estimated $11.5 \%$ (men $12.0 \%$, women $10.5 \%$ ) of smoking-related cancer cases could be prevented, if a combination of the observed tobacco control policy interventions were to be implemented in Germany. The most effective single intervention was found to be annual $10 \%$ price increases in cigarettes over 10 years, which may prevent about $6.8 \%$ of cancer cases (men 7.2\%, women 6.3\%), followed by plain packaging (men 3.8\%, women 3.3\%), a comprehensive marketing ban (men 2.0\%, women $1.7 \%$ ), and a single $10 \%$ price increase (men 1.0\%, women 0.9\%). The highest PIFs for all interventions combined were observed for lung cancer (men $16.8 \%$, women $16.4 \%$ ), cancer of the larynx (men $15.9 \%$, women 15.6\%), and the oral cavity (men 15.3\%, women $13.8 \%)$.

Conclusion Although our simulation model relies on several assumptions, this modelling approach allows a comparison of the impact of different policy intervention scenarios on future cancer incidence. Our results suggest that the expected cancer incidence in Germany could be considerably reduced by implementing tobacco control policies as part of a primary cancer prevention strategy.

\section{Food Policy}

\section{OP06 THE IMPACT OF THE ANNOUNCEMENT OF THE UK SOFT DRINKS INDUSTRY LEVY ON HOUSEHOLD SOFT DRINKS PURCHASES}

D Pell*, TL Penney, O Mytton, M White, J Adams. UKCRC Centre for Diet and Activity Research (CEDAR), MRC Epidemiology Unit, Cambridge, UK

\subsection{6/jech-2019-SSMabstracts.6}

Rationale The UK Soft Drinks Industry Levy (SDIL) was introduced in response to evidence on the role of sugary drinks in obesity, diabetes and tooth decay. The levy is two-tiered: $£ 0.24 / \mathrm{L}$ for drinks containing $>8 \mathrm{~g} / 100 \mathrm{ml}$ of added sugar and $£ 0.18 / \mathrm{L}$ for drinks containing $5-8 \mathrm{~g}$ sugar/100 $\mathrm{ml}$, and directed at manufacturers and importers of soft drinks, in order to encourage reformulation. The levy came into effect in April 2018, but was announced two years before to allow industry time to adapt. The announcement may represent a public health intervention itself.

Aim To examine change in the volume of, and amount of sugar from, household purchases of soft drinks from two years before announcement of the SDIL to two years after.

Methods An interrupted time series design was used. Kantar WorldPanel data from $\sim 43,000$ UK households recorded all food and drink purchases brought home, covering April 2014 to March 2018 (208 weeks). Outcomes were purchased volume of, and sugar from, liable soft drinks in each levy tier as well as non-liable soft drinks and confectionery (a potential high sugar substitute category) per household per week, modelled against the counterfactual of no announcement. Household purchases of toiletries (shampoo, conditioner and liquid soap) were included as a comparator. Regression analyses were weighted to reflect UK purchasing patterns.
Results Immediately after the announcement there was an increase in the volume of $(73 \mathrm{ml}$ per household per week, 95\%CI: 29,119), and amount of sugar from $(11.0 \mathrm{~g}$ per household per week, 95\%CI: 3.7, 18.4), higher tier drinks and a decrease in the amount of sugar from confectionery (24.6 g per household per week, 95\% CI: -47.1,-2.15). In the period following the announcement there was a significant downward trend in the volume of $(0.01 \mathrm{ml}$ per household per week ${ }^{2}, 95 \% \mathrm{CI}$ : $\left.-0.02,-0.01\right)$, and amount of sugar ($0.0008 \mathrm{~g}$ per household per week $\left.{ }^{2}, 95 \% \mathrm{CI}:-0.0012,-0.0004\right)$ from, drinks in the lower tier. During the same period sugar from non-liable soft drinks increased $(0.0003 \mathrm{~g}$ per household per week ${ }^{2}, 95 \%$ CI: $\left.0.00001,0.00064\right)$

Conclusion The announcement of the SDIL was associated with sustained reductions in the volume of, and amount of sugar from, drinks in the lower levy tier purchased by UK households; and a sustained increase in the amount of sugar from non-liable soft drinks. This likely reflects reformulation by manufacturers so that many drinks previously in the lower tier are now non-liable but still contain sugar. There was no evidence of substitution to confectionary.

\section{OP07 CHANGES IN THE SUGAR CONTENT OF FOOD PURCHASES AND SOCIO-ECONOMIC INEQUALITIES: A LONGITUDINAL STUDY OF BRITISH HOUSEHOLDS, 2014-2017}

${ }^{1} \mathrm{~N}$ Berger*, 'S Cummins, ${ }^{2,3} \mathrm{R}$ Smith, 'L Cornelsen. 'Department of Public Health, Environments and Society, London School of Hygiene and Tropical Medicine, London, UK: ${ }^{2}$ College of Medicine and Health, University of Exeter, Exeter, UK; ${ }^{3}$ Faculty of Public Health and Policy, London School of Hygiene and Tropical Medicine, London, UK

\subsection{6/jech-2019-SSMabstracts.7}

Background The majority of the UK population fall short of meeting dietary recommendations. This has led to a recent policy focus on improving population diet through reducing sugar consumption. This study aims to explore whether there have been recent changes in the sugar content of take-home food and beverage purchases. We assess whether these changes differ by socio-economic position (SEP).

Methods We used 2014 to 2017 data from the Kantar Worldpanel UK, a nationally representative panel study of food and beverages bought by British households and brought into the home ( $\approx \approx 32,000$ per year). Households used hand-held barcode scanners to report purchases of over 151 million food and beverage products, for which total sugar content was obtained. We used linear mixed models to estimate annual changes in the average sugar content of daily purchases by occupational social grade (high-SEP: A/B, mid-SEP: C1/C2 and low-SEP: D/E) from 24 healthier and less healthy food groups defined using the UK Department of Health nutrient profiling model. Results were adjusted for potential socio-demographic confounders. Final sample included 282,712 quarter-observations from 28,037 households.

Results Preliminary results show that in 2014, predicted average sugar content of daily purchases was $86.2 \mathrm{~g}$ per person (95\%CI $85.3-87.0 \mathrm{~g})$ in high-SEP, $87.3 \mathrm{~g}$ (95\%CI 68.8-87.9 $\mathrm{g})$ in mid-SEP, and $89.4 \mathrm{~g}$ (95\%CI 88.7-90.2 g) in low-SEP households. By 2017, this had decreased by an average of 7.1 $\mathrm{g}$ per person $(95 \% \mathrm{CI} 6.8-7.4 \mathrm{~g})$ with a greater decrease observed in low-SEP households $(8.2 \mathrm{~g}, 95 \% \mathrm{CI} 7.6-8.7 \mathrm{~g})$ compared to mid-SEP (6.9 g, 95\%CI 6.5-7.2 g) and high-SEP $(6.5 \mathrm{~g}, 95 \% \mathrm{CI} 5.9-7.0 \mathrm{~g})$ households. This decrease is largely 
due to reductions in sugar purchased from less healthy food groups (incl. sugary drinks and table sugar), and was similar in magnitude across SEP households (-6.4 to $-5.4 \mathrm{~g}$ ). However, in 2017, the amount of sugar purchased from less healthy products which usually contain higher levels of added sugar was still $3.5 \mathrm{~g}$ (95\%CI 2.7-4.3 g) higher in low-SEP compared to high-SEP households.

Conclusion There has been a $7.1 \mathrm{~g}$ per person per day reduction of total sugar purchased to take-home between 2014 and 2017. Relatively larger reductions were observed among lowSEP households. This means that by 2017, SEP differences in the total amount of sugar purchased were no longer statistically significant. However, low-SEP households continued to purchase greater amount of sugar from less healthy products in comparison to mid- and high-SEP households. Future work should identify if these changes are triggered by consumer behaviour and/or changes in products.

\section{OP08 A DISCOURSE NETWORK ANALYSIS OF UK NEWSPAPER COVERAGE OF THE 'SUGAR TAX' DEBATE BEFORE AND AFTER THE ANNOUNCEMENT OF THE SOFT DRINKS INDUSTRY LEVY}

${ }^{1} \mathrm{CH}$ Buckton*, ${ }^{1} \mathrm{G}$ Fergie, ${ }^{1} \mathrm{P}$ Leifeld, ${ }^{2} \mathrm{~S}$ Hilton. ${ }^{1} \mathrm{MRC} / \mathrm{CSO}$ Social and Public Health Sciences Unit, University of Glasgow, Glasgow, UK; ${ }^{2}$ School of Social and Political Sciences, University of Glasgow, Glasgow, UK

\subsection{6/jech-2019-SSMabstracts.8}

Background On 6th April 2018, the UK Government introduced the Soft Drinks Industry Levy (SDIL) as a policy designed to reduce population level sugar consumption and related illnesses. Given that the successful introduction of upstream food and nutrition policies is a highly political enterprise involving multiple interested parties, understanding the complex network of stakeholders seeking to influence such policy decisions is imperative.

Methods Media content analysis was employed to build a dataset of relevant articles from UK national newspapers. These articles were analysed to identify stakeholder agreement or disagreement with defined concept statements. Discourse network analysis enabled us to produce visual representations of the network of stakeholders and coalitions evident in the debate, in the months leading up to and following the announcement of the SDIL (May 2015 to November 2016).

Results Coding identified 3,883 statements made by 214 individuals from 176 organisations, relating to 47 concepts. Network visualisations revealed a complex network of stakeholders with opposing and supporting policy coalitions. Polarisation of stakeholders arose from three key factors: (i) differences in political ideology influencing the acceptability of policy options; (ii) position on a specific policy intervention; and (iii) interpretation of the evidence supporting the policy option. Industry stakeholders appeared less united in the network before the SDIL announcement, compared with the later period. Some key industry actors appeared in the supportive coalition, possibly due to the use of corporate social responsibility rhetoric. Jamie Oliver appeared as a dominant stakeholder, firmly embedded with public health advocates, suggestive of his role as a policy entrepreneur.

Conclusion This study highlights the complexity of the network of stakeholders involved in the public debate on food policies such as sugar tax and the SDIL. Public health advocates seeking to gain support for future upstream regulation to promote population health would benefit from tailoring their communication to take advantage of sources of polarisation. Vocal celebrity policy entrepreneurs may be instrumental to facilitate alignment of stakeholders around a clear ideology.

\section{OP09 IMPACTS OF POST-BREXIT AGRICULTURAL POLICY ON FRUIT AND VEGETABLE INTAKE AND CARDIOVASCULAR DISEASE IN ENGLAND: A MODELLING ANALYSIS}

${ }^{1} \mathrm{P}$ Seferidi, ${ }^{1} \mathrm{AA}$ Laverty ${ }^{*},{ }^{1},{ }^{2} \mathrm{~J}$ Pearson-Stuttard, ${ }^{2} \mathrm{~B}$ Collins, ${ }^{2} \mathrm{P}$ Bandosz, ${ }^{2} \mathrm{~S}$ Capewell, ${ }^{2} \mathrm{M}$ O'Flaherty, ${ }^{1} \mathrm{C}$ Millett. ${ }^{1}$ Public Health Policy Evaluation Unit, School of Public Health, Imperial College London, London, UK; ${ }^{2}$ Public Health and Policy, University of Liverpool, Liverpool, UK

\subsection{6/jech-2019-SSMabstracts.9}

Background Brexit might produce a new agricultural regime in the UK. The current Agriculture Bill, which will shape this regime, aims to provide financial assistance for the delivery of environmental aims. However, the current Bill may represent a missed opportunity to positively influence food systems and improve public health. Potential health-improving measures could include expanding the UK production of fruits and vegetables $(\mathrm{F} \& \mathrm{~V})$, thus increasing $\mathrm{F} \& \mathrm{~V}$ availability and affordability. Currently, only $1.4 \%$ of total agricultural land in England is allocated to F\&V. This study aims to estimate the potential impacts of allocating additional land to $\mathrm{F} \& \mathrm{~V}$ production on $\mathrm{F} \& \mathrm{~V}$ intake and associated cardiovascular disease (CVD) and inequalities in England between 2021 and 2030.

Methods We used the previously validated IMPACT Food Policy model. We translated changes in land allocated to $\mathrm{F} \& \mathrm{~V}$ into changes in F\&V intake and associated CVD mortality, expressed in number of deaths prevented or postponed by age group, sex, and Index of Multiple Deprivation (IMD) quintile. The model combined publicly available data on agricultural land use and quality, F\&V supply, waste, purchases and IMDstratified intake, IMD-stratified CVD projections, and appropriate relative risks. We modelled two scenarios that assumed a linear increase in agricultural land allocated to F\&V between 2021 and 2027 (the implementation period of the new policy) until it covers (a) $10 \%$ and (b) $20 \%$ of all high quality land suitable for production of horticultural crops in England. We assumed that F\&V prices would drop to a new market equilibrium. We used Monte-Carlo simulations to produce uncertainty intervals.

Results Our model suggested that by 2030, fruit intake might increase by approximately 4\% (95\% Uncertainty Interval: 2\%$7 \%)$ and vegetable intake by approximately $8 \% \quad(4 \%-13 \%)$ under the first scenario. Under the second scenario, fruit intake could increase by approximately 17\% (10\%-29\%) and vegetable intake by approximately 37\% (26\%-51\%). These increases in F\&V intake might prevent or postpone approximately 3,360 (1,760-5,920) CVD deaths under the first scenario and $15,700 \quad(9,000-24,310)$ CVD deaths under the second scenario, between 2021 and 2030. Our modelled scenarios could also reduce inequalities, with some $16 \%$ of these fewer deaths occurring in the most affluent group compared with $22 \%$ in the most deprived group.

Conclusion Policymakers should urgently consider the public health impacts of the post-Brexit agricultural regime in England. Increasing the land allocated to $F \& V$ production could substantially reduce the burden of CVD and associated inequalities. 